\title{
Perancangan Sistem Informasi Pendaftaran Organisasi Unit Kegiatan Khusus Berbasis Web di IAIN Bukittinggi
}

\author{
Miftahul Jannah \\ IAIN Bukittinggi \\ e-mail: miiftahuljannah32@gmail.com
}

\begin{abstract}
Abstrak
Perkembangan teknologi di era modern saat ini mengalami kemajuan yang sangat pesat, dimana setiap orang dapat menemui informasi dengan cepat. Kebutuhan informasi yang cepat dan akurat juga dibutuhkan dalam sebuah organisasi. IAIN Bukittinggi merupakan perguruan tinggi yang memiliki banyak organisasi yang dirumpun menjadi satu wadah dinamakan Unit Kegiatan Khusus (UKK). Untuk dapat meningkatkan mutu dari organisasi maka dibutuhkan sebuah system informasi pendaftaran organisasi bagi anggota baru dan bagi panitia organisasi dalam meningkatkan minat mahasiswa untuk bergabung kedalam sebuah organisasi. tujuan dirancangnya system informasi ini untuk dapat mengelola data organisasi dalam menjalankan masing-masing organisasi. Dalam perancangan system organisasi ini digunakan metode pengembangan system waterfall. Alat yang digunakan dalam desain pengembangan system ini adalah UML dengan bahasa program yang digunakan PHP dan database Mysql. Hasil dari penelitian ini adalah penggunaan system informasi pendaftaran organisasi dapat memberikan kemudahan mahasiswa dalam mendapatkan informasi serta dengan mudah dalam mendaftar sebagai anggota baru dalam organisasi dan bagi pengelola organisasi dapat dengan mudah dan rapi dalam penyimpatan data anggota organisasi.
\end{abstract}

Kata Kunci: Perancangan Sistem Informasi, Sistem Informasi Pendaftaran, UML, UKK, Waterfall, PHP/MySQL

\begin{abstract}
The development of technology in the modern era is experiencing rapid progress, where everyone can meet information quickly. Fast and accurate information needs are also needed in an organization. Bukittinggi IAIN is a college that has many organizations that are organized into one container called the Special Activity Unit (UKK). To be able to improve the quality of the organization, an organization registration information system is needed for new members and for the organization committee to increase students' interest in joining an organization. the purpose of designing this information system is to be able to manage organizational data in running each organization. In designing this organizational system used the method of developing the waterfall system. The tool used in the design of the development of this system is UML with the program language used by PHP and the MySQL database. The results of this study are the use of an organization registration information system can facilitate students in getting information and easily in registering as a new member in the organization and for organization managers can be easily and neatly in the storage of data members of the organization.
\end{abstract}

Keywords: Designing Information Systems, Registration Information System, UML, UKK, Waterfall, PHP/MySQL

\section{Pendahuluan}

IImu pengetahuan merupakan aspek penting dalam kehidupan umat manusia yang berkembang dengan pesat. IImu pengetahuan tersebut, dalam perkembangannya diiringi juga dengan perkembangan teknologi dan informasi. Perkembangan teknologi di era modern saat ini mengalami kemajuan yang sangat pesat, dimana setiap orang dapat menemui berbagi teknologi di berbagai bidang di sekitar kehidupan manusia yaitu salah satunya adalah dengan adanya teknologi sistem informasi.(Akbar, Andriansyah, \& Utomo, 2016) Sistem informasi adalah suatu sistem buatan manusia yang secara umum teridri atas sekumpulan komponen berbasis komputer dan manual yang dibuat 
sedemikian rupa sertamenyediakan informasi keluaran kepada para pemakai.(Setiawan \& Mulyani, 2017) Sistem informasi dalam suatu organisasi dapat dikatakan sebagai suatu sistem yang menyediakan informasi bagi semua tingkatan dalam organisasi tersebut. Sistem ini menyimpan, mengambil, mengubah, mengolah dan mengkomunikasikan informasi yang diterima dengan menggunakan sistem informasi atau peralatan sistem lainnya. Sistem ini berfungsi juga sebagai media untuk menyediakan informasi yang berguna untuk managemen dan mendukung rencana strategi dalam organisasi. Sedangkan tujuan dari sistem informasi tersebut untuk mengumpulkan data, menyimpan dan menginformasikan kepada para pemakai (user) yang membutuhkannya.(Alyyuddin lqbal Habiby, 2017)

Dalam dunia pendidikan seperti sekolah mulai dari tingkat dasar hingga keperguruan tinggi pun dihadapkan dengan berbagai permasalahan dalam menjalankan suatu kegiatan. Mulai dari masalah yang sederhana hingga ke yang lebih kompleks, sehingga membutuhkan teknologi sistem informasi dalam menyelesaikannya agar pekerjaan lebih efisien.

IAIN Bukittinggi merupakan perguruan tinggi yang memanfaatkan teknologi informasi dalam proses pendidikan. IAIN Bukittinggi mempunyai Organisasi Kampus Yang diberi nama Unit Kegiatan Khusus (UKK). Dimana UKK ini mempunyai beberapa cabang organisasi intra dan extra kampus. Tujuan organisasi terutama institusi pendidikan khususnya adalah mendapatkan kuantitas peserta didik baik siswa maupun mahasiswa sehingga nama institusi tersebut dengan cepat dan mudah dikenal oleh masyarakat baik yang akan melanjutkan jenjang pendidikan maupun hanya sekedar untuk mendapatkan informasi.(Chandra, Studi, \& Informatika, 2015)

Permasalahan yang teridentifikasi pada IAIN Bukittinggi adalah sebagai berikut :

a. IAIN Bukittinggi mempunyai beberapa organisasi kemahasiswaan yang disebut dengan UKK. Organisasi tersebut belum memanfaatkan teknologi informasi sehingga seluruh data keorganisasian dilakukan secara manual. b. Sulit dalam mendapatkan informasi keorganisasian secara cepat, tepat dan akurat.

c. Proses pendaftaran organisasi yang ada dikampus masih dilakukan secara manual, sehingga mahasiswa merasakan malas untuk mendaftar untuk bergabung keorganisasi tersebut karena harus meluangkan waktu yang cukup lama dalam melakukan pendaftaran

Apabila permasalahan ini dibiarkan berlarut-larut maka produktivitas organisasi semakin tidak bagus. Sehingga diperlukan sistem informasi pada organisasi tersebut agar pendafataran dapat dilakukan secara online dan data organisasi dapat disimpan dengan rapi. Berdasarkan permasalahan yang peneliti lihat maka dibutuhkan sebuah software aplikasi yang diolah dengan PHP/MySQL yang akan mempermudah pendaftaran organisasi

\section{Metode Penelitian}

\subsection{Teknik Pengumpulan Data}

Dalam penelitian penulis menggunakan metode pengumpulan data adalah obeservasi, wawancara dan studi pustuka. Melalui metode ini penulis mendapat data engan sumber yang jelas guna melengkapi penelitian ini.

\section{A. Observasi}

Penulis melakukan observasi lapangan sebagai langkah awal guna mengetahui permasalahan apa yang terjadi mengenai system yang sedang berjalan.

B. Wawancara

Setelah melakukan observasi penulis melakukan wawancara dengan tujuan mengumpulkan data dengan mengajukan pertanyaan mengenai system yang sedang berjalan kepada beberapa pengurus organisasi dan beberapa orang mahasiswa.

C. Studi Pustaka

Setelah beberapa metode yang dilewati maka langkah akhir penulis melakukan studi pustaka dari berbagai buku, jurnal dengan studi literature yang berhubungan dengan perancangan system informasi berbasis web.

\subsection{Model Pengembangan Sistem}

Dalam pengembangan system metodologi yang umum digunakan adalah 
Sistem Development Life Cycle (SDLC) yang sering disebut dengan model pengembangan air terjun (waterfall). Metode waterfall merupakan model pengembangan sistem informasi yang sistematik dan sekuensial.(Sasmito, 2017) Waterfall adalah suatu proses pengembangan perangkat lunak berurutan, di mana kemajuan dipandang sebagai terus mengalir kebawah (seperti air terjun) melewati fase-fase perencanaan, pemodelan, implementasi (konstruksi),dan pengujian. Dalam pengembangannya metode waterfall memiliki beberapa tahapan yang runtut: requirement (analisis kebutuhan), design system (system design), Coding \& Testing, Penerapan Program, pemeliharaan.(Tristianto, 2018) waterfall memiliki tahap sebagai berikut :

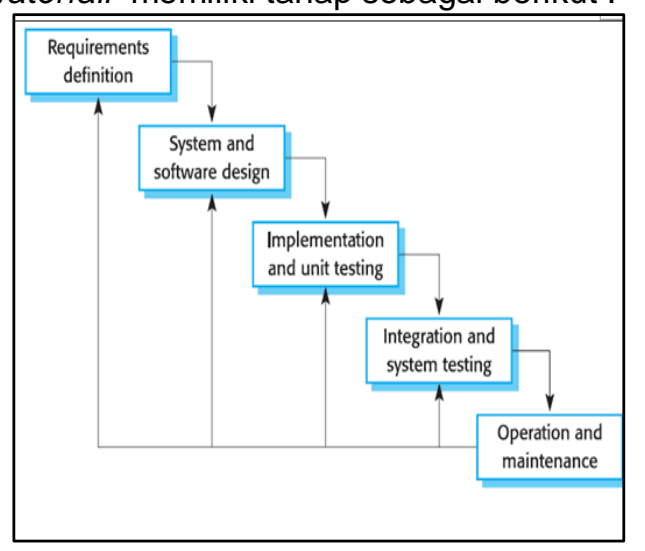

Gambar 1. Model Waterfall Sumber:Tristianto (2018)

\section{Requirement definition}

Proses pengumpulan kebutuhan dilakukan secara intensif untuk menspesifikasikan kebutuhan perangkat lunak agar dapat dipahami perangkat lunak seperti apa yang dibutuhkan oleh user.

2. Design Software and system

Desain perangkat lunak adalah proses multi langkah yang fokus pada desain pembuatan program perangkat lunak termasuk struktur data, arsitektur perangkat lunak, representasi antarmuka, dan prosedur pengkodean. Tahap ini mentranslasi kebutuhan perangkat lunak dari tahap analisis kebutuhan ke representasi desain agar dapat diimplementasikan menjadi program pada tahap selanjutnya.

3. Implementation and testing
Desain harus ditranslasikan kedalam program perangkat lunak. Hasil dari tahap ini adalah program komputer sesuai dengan desain yang telah dibuat pada tahap desain.

\section{Integration and system testing}

Pengujian fokus pada perangkat lunak secara dari segi lojik dan fungsional dan memastikan bahwa semua bagian sudah diuji. Hal ini dilakukan untuk meminimalisir kesalahan (error) dan memastika keluaran yang dihasilkan sesuai dengan yang diinginkan.

5. Operation and Implementation

Tidak menutup kemungkinan sebuah perangkat lunak mengalami perubahan ketika sudah dikirimkan ke user. Perubahan bisa terjadi karena adanya kesalahan yang muncul dan tidak terdeteksi saat pengujian atau perangkat lunak harus beradaptasi dengan lingkungan baru. Tahap pendukung atau pemeliharaan dapat mengulangi proses pengembangan mulai dari analisis spesifikasi untuk perubahan perangkat lunak yang sudah ada, tapi tidak untuk membuat perangkat lunak baru.(Tabrani \& Eni, 2017)

\section{Hasil dan Pembahasan}

Analisis masalah merupakan tahapan pertama yang harus dilakukan sebelum melakukan perancangan sistem. Melalui analisis masalah dapat diketahui pentingnya sistem yang akan dirancang. Selain itu juga dapat ditemukan hal-hal yang dibutuhkan di dalam proses perancangan sistem informasi pendaftaran organisasi Unit Kegiatan Khusus (UKK), sehingga dapat digambarkan kebutuhan yang dibutuhkan untuk perancangan sistem sistem informasi pendaftaran organisasi Unit Kegiatan Khusus (UKK) ini. Hal lain yang juga dibutuhkan selama tahapan analis masalah adalah persiapan terhadap perangkat lunak atau software dan perangkat keras atau hardware yang digunakan dalam merancang sistem informasi. Setelah menentukan model dalam penelitian ini, selanjutnya diimplementasikan kedalam langkahlangkah yang ada pada model dalam mengembangkan perancangan system.

\section{Requirement Defenition}

Pada tahap ini, penulis melakukan observasi ke organisasi Unit Kegiatan 
Khusus (UKK) di IAIN Bukittinggi, untuk mencari informasi mengenai permasalahan-permasalahan yang terjadi pada pendaftaran organisasi-organisasi tersebut, serta mengetahui kebutuhankebutuhan terhadap perbaikan sistem yang telah ada. Pencarian informasi ini dilakukan dengan wawancara dan observasi terhadap mahasiswa dan panitia yang melakukan pendaftaran organisasi, mengumpulkan berbagai dokumen yang berhubungan dengan sistem seperti data-data organisasi,data kepanitiaan organisasi, dan waktu kegiatan organisasi.

\section{Design Software and System}

Design software and system yang digunakan dalam perancangan ini adalah UML. UML (Unified Modeling Language) adalah bahasa pemodelan untuk sistem atau perangkat lunak yang berparadigma (berorientasi objek). Pemodelan (modeling) sesungguhnya digunakan untuk penyederhanaan permasalahanpermasalahan yang kompleks sedemikian rupa sehingga lebih mudah dipelajari dan dipahami(Fatmawati \& Munajat, 2018)

\section{Design Software and System}

Use Case Diagram Sistem Informasi Pendaftaran Organisasi UKK ini terbagi menjadi 3 bagian aktor yaitu, Mahasiswa, Admin masing-masing organisasi, dan super admin. Bersifat statis. Diagram ini memperlihatkan himpunan use case dan aktor-aktor (suatu jenis khusus dari kelas). Diagram ini terutama sangat penting untuk mengorganisasi dan memodelkan perilaku suatu sistem yang dibutuhkan serta diharapkan pengguna.(Dermawan, Juniadi; Hartini, 2017)

\section{Use Case Diagram Mahasiswa}

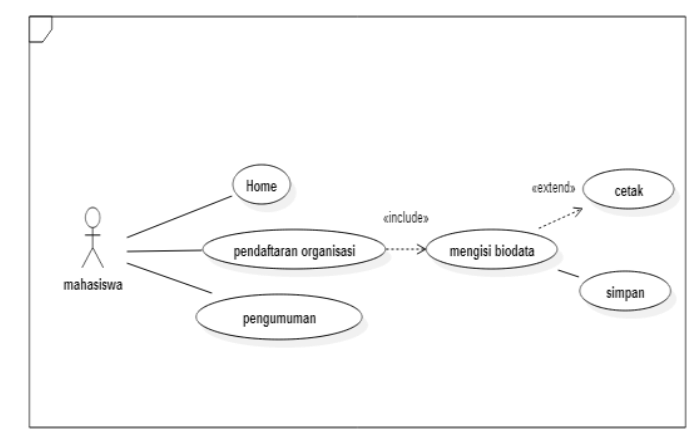

Gambar 2. Use Case Mahasiswa

\section{Use Case Diagram Admin}

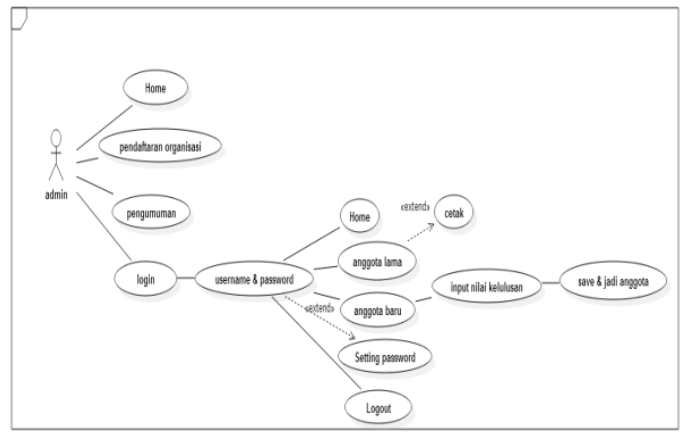

Gambar 3. Use Case Admin

3. Use Case Diagram Super Admin

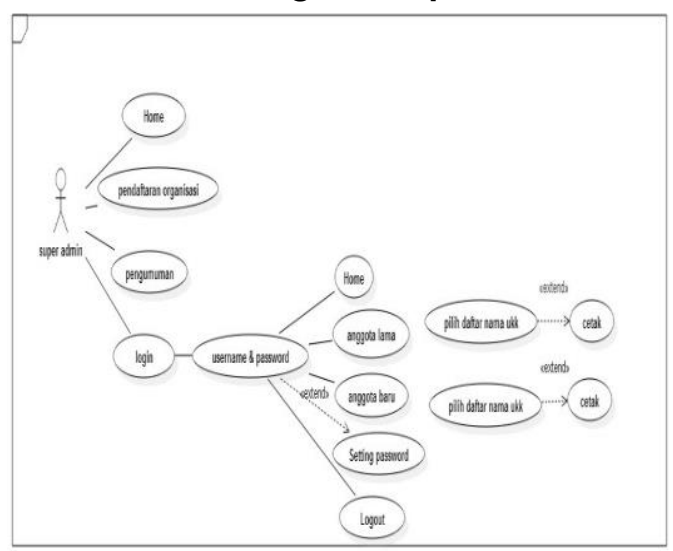

Gambar 4. Use Case Super Admin

\section{Activity Diagram}

Activity diagram mendeskripsikan seluruh aktivitas dalam sistem yang sedang dirancang, bagaimana aktivitas berawal, decision yang mungkin terjadi, dan bagaimana mereka berakhir. Bersifat dinamis. Diagram aktivitas adalah tipe khusus dari diagram status yang memperlihatkan aliran dari suatu aktivitas ke aktivitas lainnya dalam suatu sistem. Diagram ini terutama penting dalam pemodelan fungsifungsi suatu sistem dan memberi tekanan pada aliran kendali antar objek.(Dermawan, Juniadi; Hartini, 2017)

\section{Activity Diagram Mahasiswa}

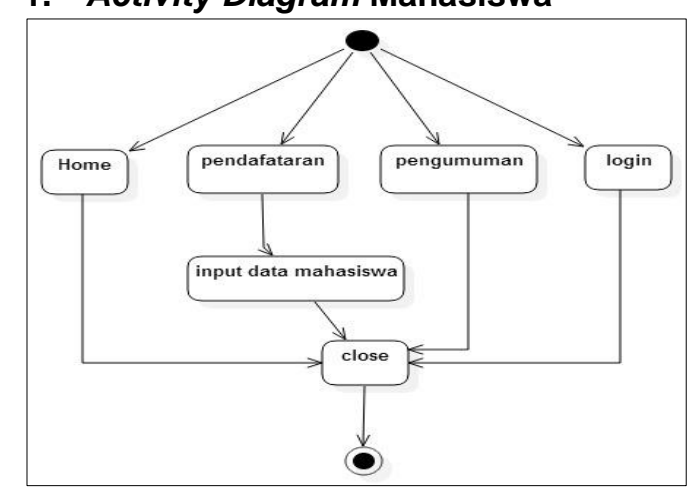

Gambar 5. Activity Diagram Mahasiswa 
Pada diagram activity ini digambarkan aktifitas mahasiswa setelah login ke system informasi, mahasiswa akan menemukan beberapa menu diantaranya Home, Pendaftaran, Pengumuman,dan logout. Pada menu home terdapat tampilan awal system informasi. Halaman home ini akan menampilkan berita-berita keseluruhan organisasi. Selanjutnya untuk menu pendaftaran mahasiswa melakukan pendaftaran organisasi dengan mengisi form yang telah disediakan. Pada menu pengumuman mahasiswa dapat melihat pengumuman kegiatan organisasi. Dan yang terakhir apabila telah selesai maka mahasiswa dapat logut dari system informasi.

\section{Activity Diagram Admin dan Super Admin}

Diagram activity admin dan super admin disatukan karena activitas yang terjadi antara admin dan super admin sama. Admin dapat melakukan kegiatan setelah login dengan menseleksi pendaftar anggota organisasi baru yang telah mendaftar dan tersimpan didalam database. Saat system menampilkan daftar nama mahasiswa yang telah melakukan pendaftaran melalui system, lalu admin melakukan tes tertulis dan tes dilapangan. Lalu admin membuat pengumuman namanama mahasiswa yang telah lulus seleksi melalui menu pengumuman dan mencetaknya sebagai arsip.

Begitu juga super admin dapat melakuka hal yang sama dalam system, hanya yang membedakan super admin dapat melihat mahasiswa yang telah mendaftar pada masing-masing organisasi UKK.

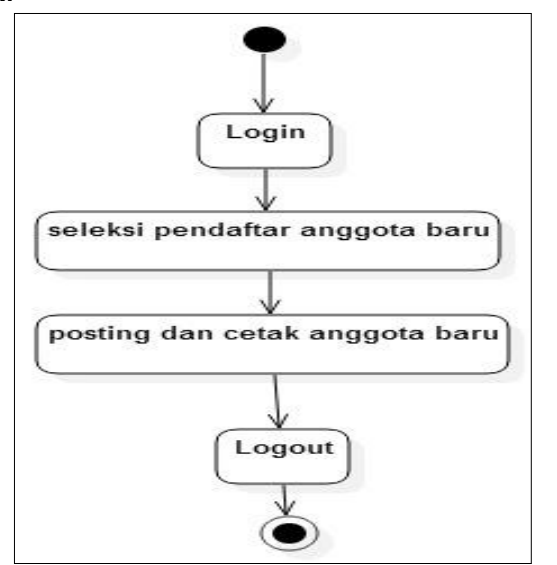

Gambar 6. Activity Diagram Admin dan Super Admin

\section{Sequence Diagram}

Suatu sequence diagram adalah suatu diagram interaksi yang menekankan pada pengaturan waktu dari pesanpesan.(Sasmito, 2017) Sequence Diagram atau Diagram Urutan Proses mengambarkan urutan proses yang dilakukan dari para pelaku sistem (aktor) termasuk komunikasi yang mungkin terjadi selama proses tersebut berlangsung(Tristianto, 2018).

\section{Sequence Diagram Mahasiswa}

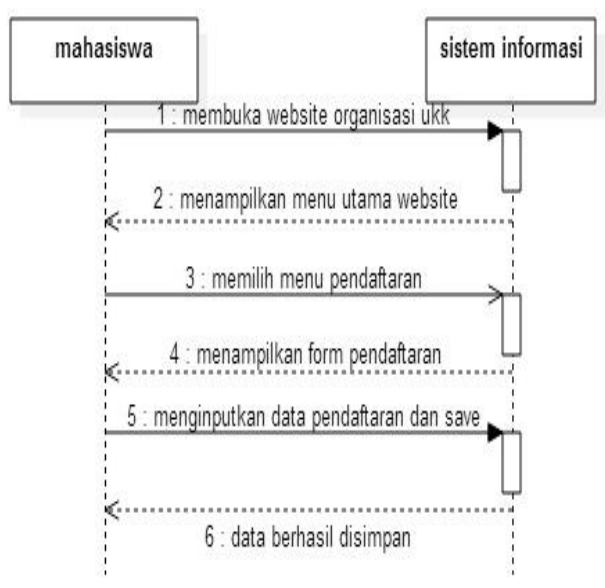

Gambar 7. Sequence Diagram

Mahasiswa

2. Sequence Diagram Admin

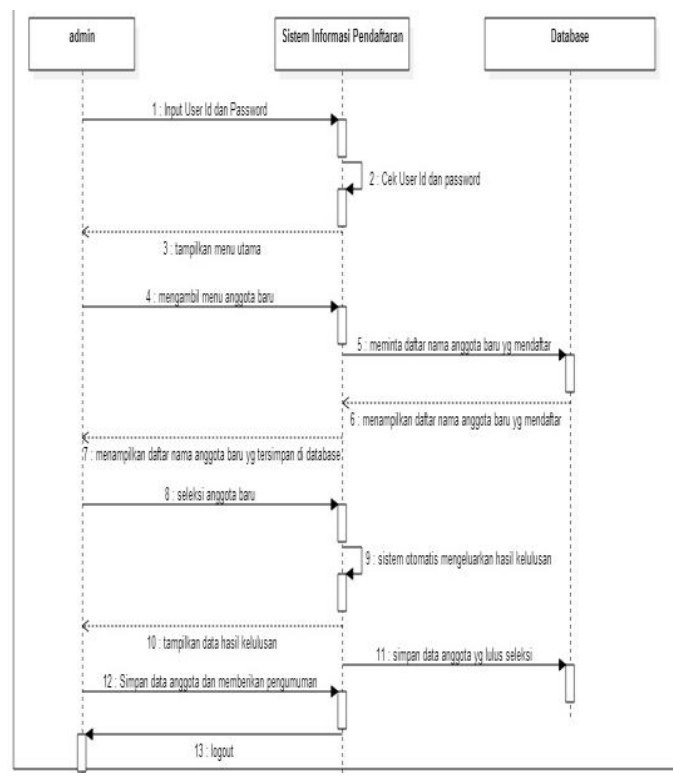

Gambar 8. Sequence Diagram Admin 
3. Sequence Diagram Super Admin

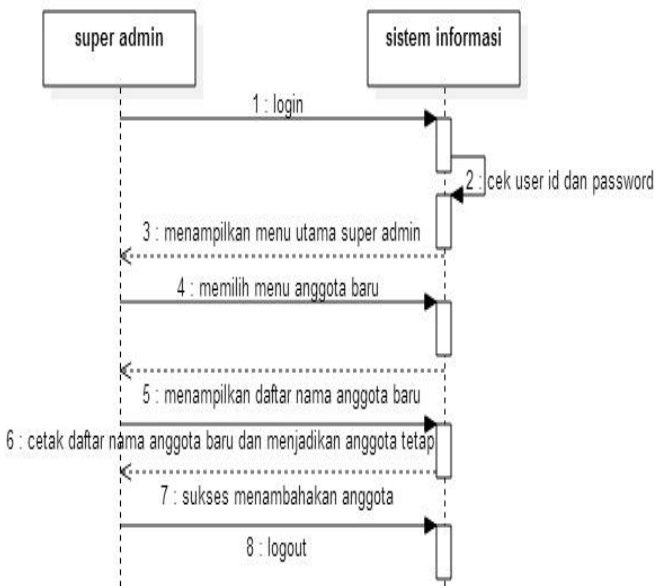

Gambar 9. Sequence Diagram Super Admin

\section{Design Software and System}

Pada proses implementasi sistem beberapa kegiatan yang dilakukan antara lain : menulis pengetahuan yang sudah direpresentasikan (disandikan) dengan bahasa pemrograman dan mendesain keamanan sistem komputer.(Sasmito, 2017) Pada tahap ini, penulis merepresentasikan desain yang telah dibuat ke dalam bahasa pemrograman melalui proses coding agar dapat dimengerti oleh mesin komputer. Pembuatan kode-kode program dan sistem ini secara keseluruan membutuhkan perangkat hardware dan software dreamwaver CS6 kedalam bahasa pemrograman PHP dan database MySQL. Hypertext Preprocessor (PHP) adalah bahasa serverside scripting yang menyatu dengan HTML untuk membuat halaman web yang dinamis(Alyyuddin lqbal Habiby, 2017) SQL adalah sebuah konsep pengoperasian basisdata, terutama untuk pemilihan atau seleksi dan pemasukan data, yang memungkinkan pengoperasian data dikerjakan dengan mudah secara otomatis(Alyyuddin lqbal Habiby, 2017) Dreamweaver merupakan salah satu software dari kelompok Macromedia yang banyak digunakan untuk mendesain situs web. Adapun Macromedia Dreamweaver itu sendiri adalah sebuah HTML editor professional yang berfungsi untuk mendesain secara visual dan mengelola situs web maupun halaman web(Melan Susanti, 2016).

\section{Integration and System Testing}

Pengujian integrasi adalah teknik untuk mengkontruksi struktur pogram dengan melakukan pengujian untuk mengungkap kesalahan sehubungan dengan menggabungkan modul-modul secara bersama-sama.(Sasmito, 2017) Setelah tahap pembuatan coding selesai, penulis melakukan percobaan terhadap sistem agar terbebas dari error dan hasilnya harus sesuai dengan kebutuhan yang sudah didefinisikan sebelumnya.

\section{Operation and Implementation}

Dalam tahapan ini, sistem diinstal dan mulai digunakan. Selain itu juga memperbaiki error yang tidak ditemukan pada tahap pembuatan. Dalam tahap ini juga dilakukan pengembangan sistem seperti penambahan fitur dan fungsi baru.(Fatmawati \& Munajat, 2018) Tahap terakhir yang harus dilakukan adalah operasi dan pemeliharaan terhadap sistem yang telah dibuat oleh admin masingmasing organisasi, seperti pengembangan sistem dan penambahan fitur-fitur yang belum ada dalam sistem.

\section{User Interface}

Setelah dilakukan desain sitem menggunakan UML dan diimplementasikan kedalam coding menggunakan software Dreamwaver CS6 maka terbentuklah hasil sebuah sistem informasi pendaftaran organisasi UKK di IAIN Bukittnggi.

\section{Tampilan Halaman Login}

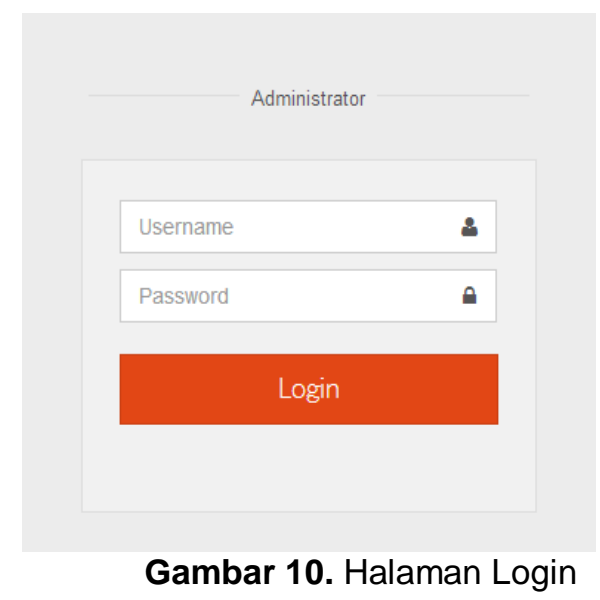

2. Tampilan Halaman Font Pendaftaran 


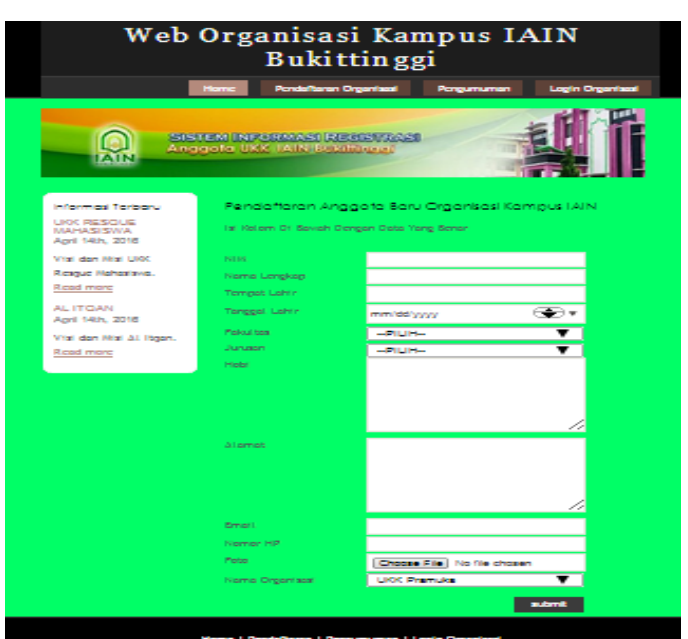

Gambar 11. Halaman Form Pendaftaran

\section{Tampilan Halaman Pengumuman Organisasi}

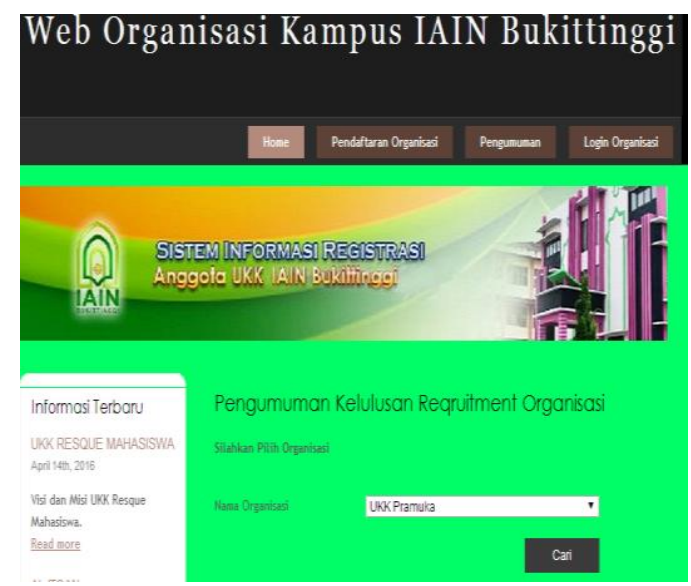

Gambar 12. Halaman Pengumuman

\section{Tampilan Halaman Cetak Bukti Pendaftaran organisasi}

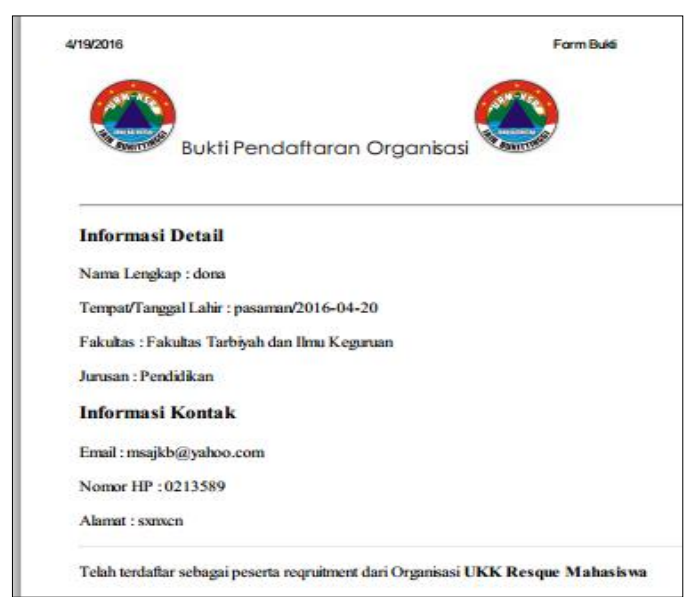

Gambar 13. Halaman Bukti Pendaftaran Organisasi

\section{Kesimpulan}

Dari hasil analisa permasalahan yang ada, maka pembuatan sistem informasi pendaftaran UKK merupakan sistem informasi yang bermanfaat bagi mahasiswa untuk memberikan informasi, serta memudahkan mahasiswa dalam melakukan pendaftaran UKK, sehingga dapat disimpulkan bahwa sistem informasi pendaftaran organisasi daapt dimanfaatkan sebagai alat untuk mempermudah anggota baru mendaftar di organisasi UKK IAIN Bukittinggi.

\section{Referensi}

Akbar, A., Andriansyah, M., \& Utomo, R. B. (2016). Perancangan Sistem Informasi Kredit Mikro Mahasiswa Berbasis Web. Jurnal Sistem Informasi (JSI), 8(1), 2355-4614. Retrieved from http://ejournal.unsri.ac.id/index.php/jsi/ index

Alyyuddin lqbal Habiby, Y. Y. (2017). SISTEM INFORMASI SEKOLAH BERBASIS WEB ( Studi Kasus: TK Kusuma Putra Kota Mojokerto ) Alyyuddin lqbal Habiby Yuni Yamasari. Sistem Informasi Sekolah Berbasis Web, 7(2), 94-100.

Chandra, T., Studi, P., \& Informatika, T. (2015). Pada Perguruan Tinggi $X$ Berbasis Web. IV(2), 31-34.

Dermawan, Juniadi; Hartini, S. (2017). Implementasi Model Waterfall Pada Pengembangan Sistem Informasi Perhitungan Nilai Mata Pelajaran Berbasis Web Pada Sekolah Dasar Al-Azhar Syifa Budi Jatibening. Paradigma, 19(2), 142.

Fatmawati, F., \& Munajat, J. (2018). Implementasi Model Waterfall Pada Sistem Informasi Persediaan Barang Berbasis Web. Media Informatika Budidarma, 2(2), 1-9. Retrieved from http://ejurnal.stmik-

budidarma.ac.id/index.php/mib/article/ view/559

Melan Susanti. (2016). Perancangan Sistem Informasi Akademik Berbasis Web Pada Smk Pasar Minggu Jakarta. Informatika, 3(1), 91-99.

Sasmito, G. W. (2017). Penerapan Metode Waterfall Pada Desain Sistem Informasi Geografis Industri Kabupaten Tegal. Jurnal Pengembangan IT, 2(1), 6-12.

Setiawan, R., \& Mulyani, A. (2017). 
Rancang Bangun Sistem Informasi Unit Kegiatan Mahasiswa Seni Dan Budaya Sekolah Tinggi Teknologi Garut. Jurnal Sekolah Tinggi Teknologi Garut, 14(2), 222-229.

Tabrani, M., \& Eni, P. (2017). Penerapan Metode Waterfall Pada Sistem Informasi Inventori Pt. Pangan Sehat Sejahtera. Jurnal Inkofar, 1(2), 30-40.

Tristianto, C. (2018). Penggunaan Metode Waterfall Untuk Pengembangan Sistem Monitoring Dan Evaluasi Pembangunan Pedesaan. Jurnal Teknologi Informasi ESIT, XII(1), 822. 